WellBeing International

WBI Studies Repository

7-1997

\title{
Vocalizations by Isolated Piglets: A Reliable Indicator of Piglet Need Directed Towards the Sow
}

\author{
Daniel M. Weary \\ Agriculture and Agri-Food Canada \\ Stephen Ross \\ Agriculture and Agri-Food Canada \\ David Fraser \\ Agriculture and Agri-Food Canada
}

Follow this and additional works at: https://www.wellbeingintlstudiesrepository.org/comski

Part of the Animal Studies Commons, Comparative Psychology Commons, and the Other Animal Sciences Commons

\section{Recommended Citation}

Weary, D. M., Ross, S., \& Fraser, D. (1997). Vocalizations by isolated piglets: a reliable indicator of piglet need directed towards the sow. Applied Animal Behaviour Science, 53(4), 249-257.

This material is brought to you for free and open access by WellBeing International. It has been accepted for inclusion by an authorized administrator of the WBI Studies Repository. For more information, please contact wbisr-info@wellbeingintl.org.

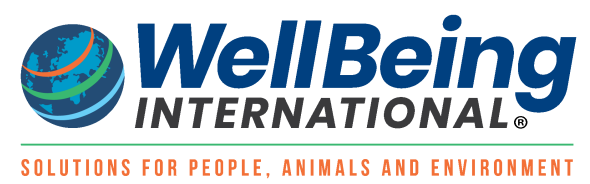




\title{
Vocalizations by Isolated Piglets: A Reliable Indicator of Piglet Need Directed Towards the Sow
}

\author{
Daniel M. Weary, Stephen Ross, David Fraser \\ Agriculture and Agri-Food Canada
}

\begin{abstract}
KEYWORDS
pigs audition, welfare, stress, vocalization, parental behaviour

ABSTRACT

When suckling piglets are isolated from the sow and litter-mates they vocalize a great deal. Sows also call when isolated from their piglets. In one experiment, we found that isolated piglets doubled their call rate in response to playback of sow calls, indicating that piglets are directing calls towards the sow. In a second experiment, we found that variation in the piglet isolation calls related to aspects of the piglet's condition: piglets isolated for $13 \mathrm{~min}$ in an enclosure kept at approximately $14^{\circ} \mathrm{C}$ called more, used higher frequency calls and longer calls, than litter-mates isolated in an enclosure kept at $30^{\circ} \mathrm{C}$. These differences in vocal behaviour were significant at 8 and 12 min of isolation, but not at 1, 2 or $4 \mathrm{~min}$. These results for pigs correspond to those found with other species, indicating that characteristics of isolation calls can provide information about a young animal's need for supplemental heat that can be supplied by the parent. The results also agree with a previous study on pigs, showing that features of these vocalizations vary with the piglet's need for other resources such as milk.
\end{abstract}

\section{Introduction}

Although several behavioural measures have been used to assess aspects of animal welfare (see Fraser, 1993), the development of reliable welfare indicators remains one of applied ethology's greatest challenges. An animal's vocalizations are one class of behaviours thought to provide some indication of its condition. For example, Darwin (1872) argued that vocalizations can provide information about a variety of emotions animals experience such as fear, pain and pleasure, and many recent authors have argued along similar lines. The idea that an animal's calls can provide an indication of its state has intuitive appeal, but in many situations it is known that calling does not provide such information (see Weary and Fraser, 1995a). Before using an animal's vocalizations as an indicator of its welfare, we should have evidence that variation in the calls does reflect variation in the animal's state. We should also have some understanding of the function of the calls in order to be able to predict the contexts in which they will be used.

One indication of whether calls are likely to provide accurate information about a caller' s condition, is that the calling meets the requirements proposed by theoretical models of 'honest signalling'. These models 
normally require that the receiver and sender be related (so that the receiver can gain a fitness benefit from any aid that it provides), and that producing the signal entails some cost (so that animals do not invest in signalling if they are not in need) (see Maynard Smith, 1991 ; Johnstone and Grafen, 1992; Godfray, 1995). As long as there are receivers that will respond, animals should be willing to invest in signalling up to the point that the cost of this investment approaches the value of any benefit from a response.

The calls given by piglets when separated from the sow (Fraser, 1975) are one candidate for a vocal indicator of welfare. The results of earlier experiments have shown that these piglet calls affect the behaviour of the sow: in response to playback of recorded isolation calls, sows responded by approaching the speaker and by vocalizing themselves (Weary and Fraser, 1995b; Weary et al., 1996). The aim of Experiment 1 was to provide further evidence that the piglet calls are directed towards the sow, by determining the effect of cues of the sow's presence on piglet calling. To do this we played recordings of sow vocalizations to isolated piglets, thus simulating the presence of a sow potentially able to hear and respond to the piglet's calls. If piglets call in an attempt to attract the sow, we expected that piglets would increase their call rate in response to playback of sow calls.

Earlier experiments have also provided some evidence that variation in these piglet isolation calls does reflect variation in the piglet's state. Weary and Fraser (1995b) measured the vocalizations of piglets temporarily isolated from the sow, and found that piglets that had missed nursing or were growing slowly relative to their birth weights vocalized more than litter-mates that had just been fed or were growing relatively well. To show that an indicator is of some general use, however, its reliability needs to be established using a number of different challenges.

The aim of Experiment 2 was, therefore, to supplement the empirical evidence for a relationship between a piglet's known physical condition and its vocalizations. Cool temperatures are one important threat to the survival of a young piglet (e.g. Mount, 1968; Curtis, 1983). In the wild, the sow is the main source of supplemental heat for the piglet, so a reduction in ambient temperature will lead to an increase in the piglet's need to be reunited with the sow. We, therefore, predicted that piglets in colder conditions would devote more effort to calling.

Fig. 1. Sonagram of one of the sow isolation calls used for playback in Experiment 1.

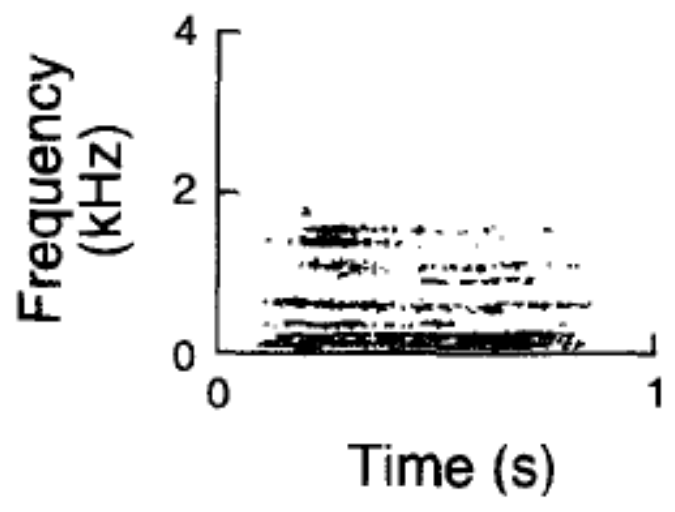

\section{Experiment 1: animals, materials and methods}

We randomly selected four piglets from each of ten litters, all from our specific-pathogen-free Landrace $x$ Yorkshire research herd. Due to recording problems during one trial, the results from only 39 subjects 
were included in the analysis. Subjects were 20 -26 days old and on average ( \pm SD) weighed $7.7 \pm 1.6$ $\mathrm{kg}$.

Playback stimulus tapes were made from recordings of three sows (not the mothers of the subjects) that had been temporarily separated from their litters. Other work in our laboratory has shown little effect of individual identity of the caller on response to playback in pigs (Weary et al., 1996), and preliminary trials had shown that piglets respond strongly to calls of both their own mother and other sows. Playback tapes were made using the calls of three different sows so as to allow us to generalize any results beyond the effect of a single sow's calls (see McGregor et al., 1992).

When sows are isolated from their piglets, either temporarily or when the piglets are removed for weaning, they produce a series of long grunts (Fig. 1). Sows were recorded during $10 \mathrm{~min}$ of isolation. So as to allow some time for the effect of isolation to stabilize, only the last $2 \mathrm{~min}$ from each sow were used for playback. Recordings were made on a Sony Hi-Fi VCR (SLV-83 494HF) via a Symetrix SX202 preamplifier and a Beyer Dynamic MCE86 N(C) microphone suspended approximately $1.5 \mathrm{~m}$ above the floor of the sow's pen. Calls used for playback were (mean \pm SD) $394 \pm 156 \mathrm{~ms}$ in duration, and the three different 2-min sequences consisted of 14,39 and 61 calls.

During each trial, a piglet was played two stimuli: one of the three 2-min sequences of sow calls and a 2min sequence of computer-generated white noise played at the same amplitude. The order of playback (noise first versus sow calls first) was determined randomly for the first piglet from each litter, and then alternated for the subsequent three. The choice of sow calls played was determined randomly in each trial. Playback was from a Sony TCD-D3 digital audio tape recorder to a Fostex SPAll loudspeaker.

Fig. 2. Mean number of calls $\min ^{-1}$ produced by piglets during Experiment 1 . Results are plotted separately by the order in which the two playback stimuli (i.e. sow calls and white noise) were presented during each trial. During half the trials piglets were played the sow calls for the first playback period (12-14 min) and white noise for the second playback period (19-21 $\mathrm{min}$ ) (filled squares and solid lines). During the other trials this order was reversed (empty squares and dashed lines).

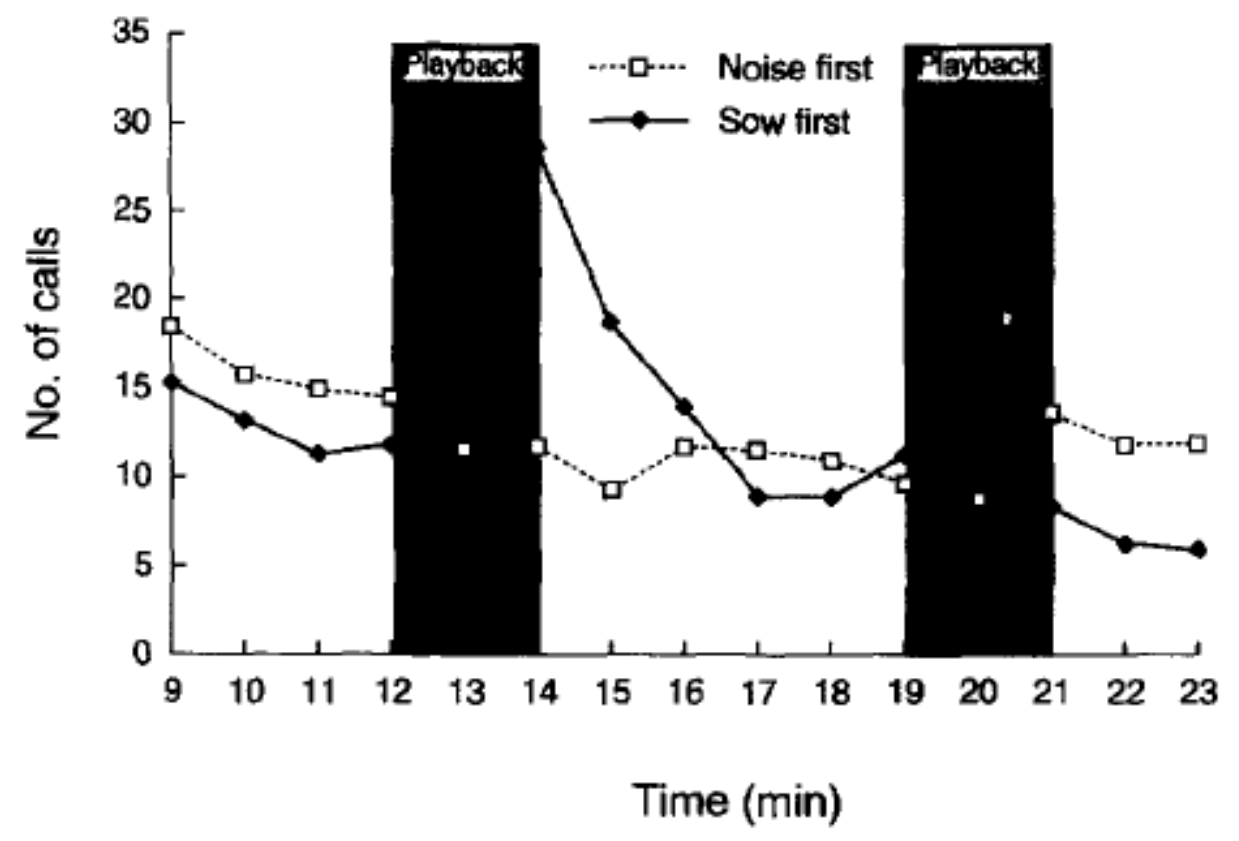


After a piglet was removed from its litter it was placed in an enclosure measuring $0.5 \times 0.5 \times 0.5 \mathrm{~m}$ and lined in soft foam rubber. The trial began with 12 min of silence, followed by 2 min of playback, 5 min of silence and a second 2 min of playback. After a further 2 min of silence (i.e. 23 min after the trial began) the piglet was returned to the sow and its litter-mates. The test room was kept at approximately $26^{\circ} \mathrm{C}$. Piglet vocalizations were recorded using a Beyerdynamic MCE $86 \mathrm{~N}(\mathrm{C})$ microphone placed $10 \mathrm{~cm}$ above the top of the pen. The signal from the microphone was fed to a Sony TCD-D3 digital audio tape recorder via a Symetrix SX202 preamplifier.

We counted the number of calls produced during playback and I min immediately after playback, and compared this count for the two playbacks within each trial. The analysis of variance model included litter (9 d.f.), order (sow calls vs white noise played first, 1 d.f.) and sow calls (which of the three sows' calls were played, 2 d.f.) as between-subject effects, tested against an error term with 26 d.f. Playback stimulus (sow calls vs white noise, 1 d.f.), as well as the stimulus by litter, stimulus by order and stimulus by sow calls interactions were tested as within-subject effects against a second error term also with 26 d.f.

\section{Experiment 1: results}

There was a gradual decline in the rate of calling by piglets over the entire period of isolation (Fig. 2). The mean call rate of the isolated piglets was more than double during playback of sow calls than during playback of noise when the sow calls were played first. When sow calls were presented after the sequence of white noise the increase in call rate was much less, perhaps as a result of habituation to playback or the longer period of isolation. The call rate of piglets showed a slight decline during playback of white noise, following the overall decline in call rate with time. Statistically, these results were reflected in significant interaction between the effect of playback stimulus and order $(F=11.50$, d.f. $=1,26, P<$ 0.003 ). There was no significant difference in response to the calls from the three different sows $(F=$ 0.57 , d.f. $=2,26, P>0.2$ ).

\section{Experiment 2: animals, materials and methods}

This experiment was performed on 54 piglets from 20 litters, all from the same research herd used in Experiment 1. Piglets were tested at 9-11 days of age, and weighed on average ( \pm SD) $3.6 \pm 0.8 \mathrm{~kg}$. Pairs of piglets were matched for weight, removed from the litter simultaneously and randomly allocated to two visually and acoustically isolated enclosures differing in temperature. Enclosures were identical to that described for Experiment 1, and were kept at approximately $14^{\circ} \mathrm{C}$ in environmentally controlled rooms. One of the enclosures received supplemental heat from a $250-\mathrm{W}$ Sylvania infrared heat lamp placed at approximately $0.8 \mathrm{~m}$ above the floor of the box. This additional heat resulted in the 'warm' enclosure having an average temperature of $29.9 \pm 1.2^{\circ} \mathrm{C}$ while the 'cool' enclosure averaged $13.8 \pm 0.9^{\circ} \mathrm{C}$. Temperatures were measured to $\pm 0.1^{\circ} \mathrm{C}$ using an electronic probe (Micronata min.-max. digital thermometer) resting on the centre of the dark, carpeted surface on the base of the box. The heat lamp was moved between the two enclosures, such that the temperature treatment was balanced across the two enclosures.

After the piglets were placed in the enclosures, they were recorded simultaneously for a period of 13 min using the recording equipment described for Experiment 1 . All calls produced during the first $16 \mathrm{~s}$ of the first, second, fourth, eighth and twelfth minutes of recording (a total of 4142 calls) were counted and measured using Signal software (Engineering Design, 1991). For each sample period we measured the number of calls, and for each call we measured the duration $(\mathrm{ms})$, and the frequency $(\mathrm{kHz})$ of maximum amplitude (i.e. frequency of the loudest band in the call). These measures were chosen because they had proven useful in an earlier study (Weary and Fraser, 1995b). 
Each of the 27 pairs of piglets $(N=27)$ was tested twice on consecutive days, according to a cross-over design (Cochran and Cox, 1992). One piglet from each pair was tested in the warm enclosure on the first day and the cool enclosure on the second, while the other piglet of the pair had the reverse order. The analysis of variance model incorporated the effects of pair of piglets (26 d.f.), piglet within pair (27 d.f.) and day (i.e. first trial or second, 1 d.f.) tested against the order by pair interaction (26 d.f.); as well as temperature (1 d.f.) tested against an error term with 26 d.f. In preliminary analyses the effect of piglet sex was tested but found not to be significant.

Fig. 3. Calls uttered by piglets in 'warm' (solid squares and dashed lines) and 'cool' (empty squares and solid lines) conditions during the first $16 \mathrm{~s}$ of each of the five 1-min periods sampled. Call measures are the mean $( \pm S E)(A)$ number of calls, (B) frequency of loudest band and (C) duration. Data are from the first trial performed on each piglet.
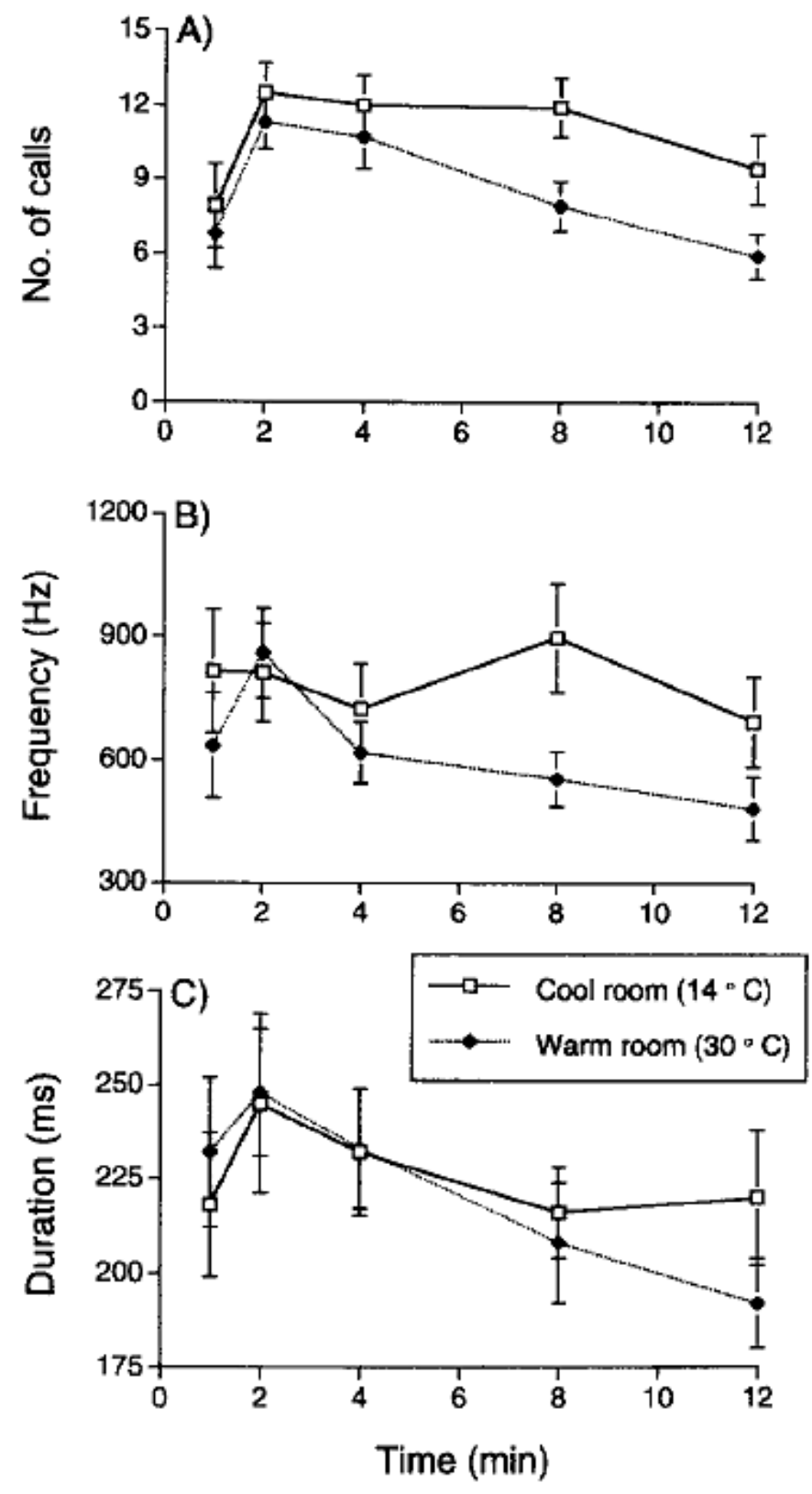


\section{Experiment 2: results}

Piglets called more when isolated in a cool enclosure than in a relatively warm one $(F=6.60$, d.f. $=1,26$, $P<0.02$ ). However, piglets called at a rate of only 22 calls $\mathrm{min}^{-1}$ during the second trial compared with a rate of 39 calls $\mathrm{min}^{-1}$ during the first, resulting in a highly significant effect of the day in which piglets were exposed to the two treatments $(F=69.05$, d.f. $=1,26, P<0.001)$. The effect of temperature was significant during the first trial $(F=4.04$, d.f. $=1,26, P<0.05)$ but not the second $(F=0.11$, d.f. $=1,26$, $N S)$, so subsequent analyses focused on the results from the first trial only.

The difference in response to the two conditions was not constant across the 13 min of the trial, but rather increased with time (Fig. 3). We found no significant difference in the number of calls used by piglets in the two treatments for Minutes 1,2 or $4(F<2.26$, d.f. $=1,26$, NS; Fig. 3a). However, piglets called significantly more in the cool enclosure during Minute $8(F=6.71$, d.f. $=1,26, P<0.02)$ and Minute $12(F$ $=5.37$, d.f. $=1,26, P<0.03$ ).

Call frequency was higher and call duration longer in the cool room. As there was a stronger effect of temperature for the first trial than for the second, we restricted our analysis to the first for these measures as well. As with the number of calls, these measures showed the largest differences between the two conditions after the first few minutes of the trial (Fig. 3(b), (c)). There were no significant differences between conditions for either of the variables during Minutes 1,2 or $4(F<2.26, d . f .=1,26$, NS), but calls from piglets in the cool condition were of higher frequency during Minute 8 ( $F=5.63$, d.f. $=1,26, P<$ 0.03 ), and longer during Minute $12(F=5.16$, d.f. $=1,26, P<0.04)$, than those from piglets in the warm condition.

\section{General discussion}

If piglet isolation calls serve as a signal to the sow that helps to reunite the animals, then we might expect the amount of calling to increase when the sow is close enough to hear. This proximity could be indicated by the fact that the piglet can hear the sow's own calls. The result of Experiment 1, showing that the calling of isolated piglets increase in response to playback of sow vocalizations, is consistent with this idea. That sows respond to piglet isolation calls by vocalizing themselves and approaching the source of the calls (Weary and Fraser, 1995b; Weary et al., 1996), and sows respond more to the more extreme calling from needier animals (Weary et al., 1996), also supports the view that piglet isolation calls serve a communicative function with the sow. One other experiment (Walser, 1986) has also shown that piglets respond vocally to sow calls, although the type of sow calls used for playback was not described.

The results from Experiment 2 showed that piglets isolated in the relatively cool enclosure (about $14^{\circ} \mathrm{C}$ ) called more, and used higher frequency and longer calls, than litter-mates isolated in the warmer enclosure (about $30^{\circ} \mathrm{C}$ ). Evidence summarized by Mount (1968) shows that an ambient temperature of $30^{\circ} \mathrm{C}$ would be in or near the zone of thermoneutrality for young piglets, whereas $14^{\circ} \mathrm{C}$ would be well below. Thus, piglets in the cooler environment would lose more heat to the environment, and although they would be expected to maintain core body temperature (Mount, 1959), they would incur a higher energy cost in doing so. In the present experiment, the difference in calling between the two ambient temperatures developed only after several minutes in the apparatus, presumably as the animals lost progressively more body heat to the environment.

The pups of several species of small rodent vocalize in response to isolation from the mother (Noirot, 1972), and they call more when isolated at cool air temperatures (e.g. Blumberg and Alberts, 1990). Indeed, data from Olivier et al. (1994) show that the difference in the mean number of calls given by rat pups kept at $18^{\circ} \mathrm{C}$ versus others kept at $37^{\circ} \mathrm{C}$ increases over the course of 10 min of isolation, following 
much the same pattern to that shown for the piglets. These rodent vocalizations are mostly in the ultrasound range (»20 kHz), and fall into the range of peak sensitivity for adult listeners (e.g. Brown, 1973). Parents will respond to these calls by orienting towards them and by searching for their young (e.g. Allin and Banks, 1972).

Some of the best evidence for a relationship between calling and temperature in young isolated animals comes from studies on birds (e.g. Evans, 1990; Bogden and Evans, 1991; Wiebe and Evans, 1994). For example, Evans (1994) showed that young white pelicans (Pelecanus erythrorhynchos) increased calling as their body temperature fell. He concluded that these calls act like honest signals of need for warmth directed to parents (see Maynard Smith, 1991). Once again, other studies have shown that parents respond to this calling, in this case by brooding the chilled young (Evans, 1992).

As in our earlier experiments (Weary and Fraser, 1995b), the effects detected in Experiment 2 were subtle: a maximum increase in call rate of only $59 \%$, for example. Also, the piglets seemed to habituate to the isolation procedure, as reflected by the much reduced level of calling during the second trial that seemed to obscure differences between conditions. The subtlety of the effects calls for some caution in their interpretation. However, all three experiments in which we have monitored vocalizations in response to manipulations in the animal's condition have shown the predicted trend toward increased vocalization by piglets in greater need for the sow's response, whether need was manipulated by temperature (Experiment 2), or by short-term or long-term food deprivation (Weary and Fraser, 1995b). The value of this series of experiments (Weary and Fraser, 1995b; Weary et al., 1996; present study) is in establishing the reliability and generality of piglet isolation calls as a welfare indicator that can now be applied to new problems.

\section{Acknowledgements}

We thank Del Buckley and Marcel Lalonde for help with Signal, and Brian Thompson for help with the statistical analysis. We are grateful to Leah Braithwaite, Rodget Evans, Andy Hom, Per Jensen, Ed Pajor, Gareth Lawson, Johanne Mongrain and Allison Taylor for commenting on earlier drafts of this manuscript.

\section{References}

Allin, J.T. and Banks, E.M., 1972. Functional aspects of ultrasound production by infant albino rats (Rattus norvegicus). Anim. Behav., 20: 175-185.

Blumberg, M.S. and Alberts, J.R., 1990. Ultrasonic vocalizations by rat pups in the cold: an acoustic byproduct of laryngeal braking? Behav. Neurosci., 104: 808-817.

Brown, A.M., 1973. High levels of responsiveness from the inferior colliculus of rodents at ultrasonic frequencies. J. Comp. Psycho!., 83: 393-406.

Bugden, S.C. and Evans, R.M., 1991. Vocal responsiveness to chilling in embryonic and neonatal American coots. Wilson Bull., 103: 712-717.

Cochran, W.G. and Cox, G.M., 1992. Experimental Designs. 2nd edn., Wiley, New York.

Curtis, S.E., 1983. Environmental Management in Animal Agriculture. lowa State University Press, Ames.

Darwin, C., 1872. The Expression of the Emotions in Man and Animals. John Murray, London. Engineering Design, 1991. Signal: User's Manual. Engineering Design, Belmont, MA. 
Evans, R.M., 1990. Vocal regulation of temperature by avian embryos: a laboratory study of pipped eggs of the American white pelican. Anim. Behav., 40: 969-979.

Evans, R.M., 1992. Embryonic and neonatal vocal elicitation of parental brooding and feeding responses in American white pelicans. Anim. Behav., 44: 667-675.

Evans, R.M., 1994. Cold-induced calling and shivering in young American white pelicans: honest signalling of offspring need for warmth in a functionally integrated thermoregulatory system. Behaviour, 129: 13-34.

Fraser, D., 1975. Vocalizations of isolated piglets. II. Some environmental factors. Appl. Anim. Ethol., 2: 19-24.

Fraser, D., 1993. Assessing animal well-being: common sense, uncommon science. In: Food Animal Well-Being. Purdue University Office of Agricultural Research Programs, West Lafayette, USA, pp. 37-54.

Godfray, H.C.J., 1995. Signaling of need between parents and young: parent-offspring conflict and sibling rivalry. Am. Nat., 146: 1-24.

Johnstone, R.A. and Grafen, A., 1992. The continuous Sir Philip Sidney game: a simple model of biological signalling. J. Theor. Bioi., 156: 215-234.

Maynard Smith, J., 1991. Honest signalling: the Philip Sidney game. Anim. Behav., 42: 1034-1035.

McGregor, P.K., Catchpole, C.K., Dabelsteen, T., Falls, J.B., Fusabi, L., Gerhart, H.C., Gilbert, F., Horn, H.G., Klump, G.M., Kroodsma, D.E., Larnbrechts, M.M., McComb, K.E., Nelson, D.A., Pepperberg, I.M., Ratcliffe, L., Searcy, W.A. and Weary, D.M., 1992. Design of playback experiments: the Thombridge Hall NATO ARW consensus. In: P.K. McGregor (Editor), Playback and Studies of Animal Communication. Plenum Press, New York, pp. 1-10.

Mount, L.E., 1959. The metabolic rate of the newborn pig in relation to environmental temperature and to age. J. Physiol., 147: 333-345.

Mount, L.E., 1968. The Climatic Physiology of the Pig. Edward Arnold, London.

Noirot, E., 1972. Ultrasounds and maternal behaviour in small rodents. Develop. Psychobiol., 5: 371-387.

Olivier, B., Milewijk, E., van Oorschot, R., vanderPoel, G., Zethof, T., van der Heyden, J. and Mos, J., 1994. New animal models of anxiety. Eur. Neuropsychopharmacol., 4: 93-102.

Walser, E.E.S., 1986. Recognition of the sow's voice by neonatal piglets. Behaviour, 99: 177-188.

Weary, D.M. and Fraser, D., 1995a. Signalling need: costly signals and animal welfare assessment. Appl. Anim. Behav. Sci., 44: 139-157.

Weary, D.M. and Fraser, D., 1995b. Calling by domestic piglets: reliable signals of need? Anim. Behav., 50: 1047-1055.

Weary, D.M., Lawson, G. and Thompson, B.K., 1996. Sows show stranger responses to isolation calls of piglets associated with greater levels of piglet need. Anim. Behav., 52: 1247-1253.

Wiebe, M.O. and Evans, R.M., 1994. Development of temperature regulation in young birds: evidence for a vocal regulatory mechanism in two species of gulls (Laridae). Can. J. Zoot., 72: 427-432. 